\title{
Jellyfish fisheries in northern Vietnam
}

\author{
Jun Nishikawa ${ }^{1 *}$, Nguyen Thi Thu ${ }^{2}$, Tran Manh Ha ${ }^{2} \&$ Pham The Thu ${ }^{2}$ \\ ${ }^{1}$ Ocean Research Institute, University of Tokyo, 1-15-1, Minamidai, Tokyo 164-8639, Japan \\ ${ }^{2}$ Institute of Marine Environment and Resources, 246 Danang Street, Haiphong City, Vietnam
}

Received 3 June 2008, Accepted 28 August 2008

\begin{abstract}
The aim of this study is to describe jellyfish fisheries (JF) in Thanh Hoa, the northern part of Vietnam. Information was accumulated based on an interview with the owner of a private jellyfish processing factory (JPF) and fishermen, sampling animals, and through reports of fishery statistics. The JF season begins in April and finishes in May. Two species, Rhopilema hispidum and Rhopilema esculentum are confirmed as commercially exploited, with the former species being caught in much higher abundance than the latter. Cyanea, Chrysaora, Sanderia, and Aequorea were also by caught but not used for processing. Jellyfish are cut into three parts, the bell, the oral-arms, and the stem (fused part of the oral-arm), which are processed separately using salt and alum at the JPF. The number of Rhopilema jellyfish collected by fishermen is estimated as 800,000-1,200,000 indiv. per fishery season, suggesting that the fishery may have an impact on jellyfish populations in the area. On the other hand, the JF has resulted in substantial economic benefits to fishermen, the JPF and thus the local economy. In a jellyfish-rich year, the income of fisherman can reach 31-75 USD day ${ }^{-1}$ or 1,200-3,000 USD during the JF season, which could sustain their living for the rest of the year. However, the JF also put fishermen into a financially unstable condition because they have to rely on jellyfish occurrence, which shows high inter-annual variation, and market price set by brokers who purchase their product. Statistics provided by the Sea Product Processing Company indicates that the export amount of jellyfish tripled from a total of 1,500 tones in 1995 to 4,600 tones in 2005 .
\end{abstract}

Key words: fisheries, jellyfish, processing, Rhopilema, Vietnam

\section{Introduction}

Population increases and the mass occurrence of pelagic cnidarians at various time-scales have been reported in various parts of the world's oceans (reviewed by Mills 2001, Purcell 2005, Purcell et al. 2007). While jellyfish swarms sometimes have negative impacts on human activities, such as damage to fishing gear and/or fishery products (e.g. Omori 1978, Kawahara et al. 2006), the clogging of water intake systems of electric power plants (e.g. Matsueda 1969), and stinging swimmers at the beach (see Purcell et al. 2007 for references), some species have been beneficial to humans because they have been utilized as food, especially in Chinese cuisine (e.g. Hon et al. 1978, Omori 1981, Omori \& Nakano 2001).

At least eight species of jellyfishes that belong to the order Rhizostomeae, class Scyphozoa, have been commercially harvested in Southeast Asia (Kingsford et al. 2000, Omori \& Nakano 2001). They are caught by various kinds of fishing gear including setnets, drift-nets, hand-nets,

\footnotetext{
*Corresponding author: Jun Nishikawa; E-mail: jn@ori.u-tokyo.ac.jp
}

scoop-nets, beach-seines and hooks. The fishery is primarily characterized by large fluctuations in annual catch and a short fishing season that is restricted from two to four months. However, the economic value of jellyfish to the fishermen or jellyfish processing companies, and thus the local economies, are not well known.

In Vietnam, jellyfish fisheries started rather recently compared with those in Southeast Asian countries such as Thailand, Malaysia and Indonesia, probably after the 1970s (Omori \& Nakano 2001). Three main areas, the Gulf of Tonkin area, Cam Ranh in the South China Sea, and Phu Quoc Island in the Gulf of Thailand are known as jellyfish fishing grounds (Omori \& Nakano 2001, Fig. 1). However, with the exception of local knowledge within fishing communities and processing plants, little detailed information is known on collection and processing methods, and the income of fishermen and the processing company, for this potentially commercially important fishery. A detailed description of the fishery from fishing methods to economics is important in assessing its importance to the local economy and how interannual variations in jellyfish catch may impact the fishery. 


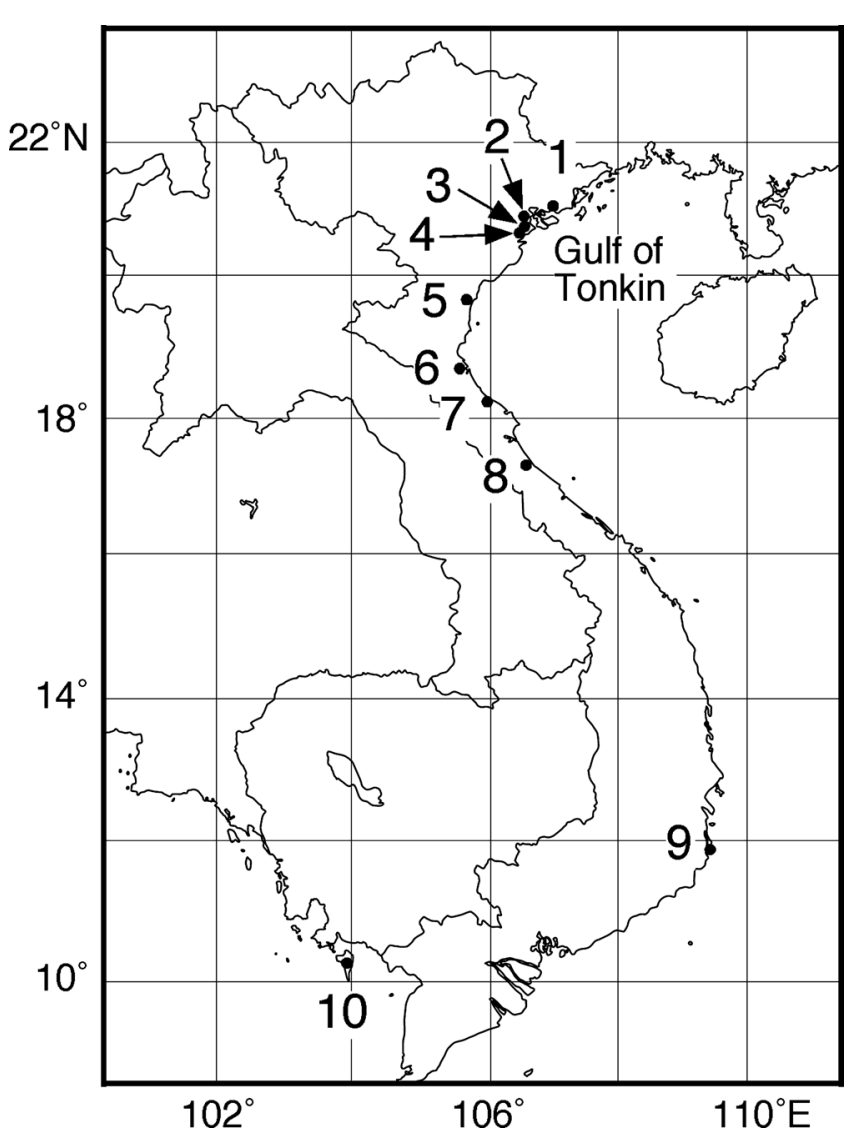

Fig. 1. Location of areas mentioned in the present study in Vietnam. 1. Quang Ninh, 2. Haiphong (Hai Phong), 3. Thai Binh, 4. Nam Dinh, 5. Thanh Hoa, 6. Nghe An, 7. Ha Tinh, 8. Quang Binh, 9. Cam Ranh, 10. Phu Quoc Island.

This study is the first detailed report of the jellyfish fishery in Vietnam. The fisheries were investigated in three ways: through interviews with owners of a jellyfish processing factory, field sampling of jellyfish species caught by fishermen, and the investigation of fishery statistics officially recorded in Haiphong City and Nam Dinh Province.

\section{Materials and Methods}

\section{Interview with the owner of a processing factory and fishermen}

To describe the jellyfish fisheries and processing procedures, we repeatedly visited one of the jellyfish processing factories located in Thon 5, Thanh Minh Village, Quang Vinh Commune, Quang Xuong District in Thanh Hoa Province from April 2006 to May 2007 (Fig. 1). Over several times we interviewed the owner of a jellyfish processing factory (JPF), Mr. Vu Tien Quang. On every occasion Mr. Quang kindly answered our questions, and he showed us his factory. During the fishing season additional interviews were also carried out with several fishermen who work for Mr. Quang's JPF. Because information in this study largely depends on comments made by the interviewees, we tried to obtain all information as precisely as possible. As a result, we confirmed the accuracy of interviewee's comments by repeating the same questions at different periods during the 2 years of this study. In this study, currency conversions from Vietnamese Dong (VND) to U.S. Dollar (USD) were made to express the economic aspects using a factor of $1 \mathrm{USD}=16,000 \mathrm{VND}$.

\section{Sampling at sea}

Jellyfish sampling was carried out in April 20, 2006 and April 21, 2007 by using fishery boats with fishermen at the fishing grounds located approximately $4-5 \mathrm{~km}$ from the shore along the sandy coast of Thanh Hoa (Fig. 1). Portions of jellyfish caught by fishermen were sampled. Additional samples were obtained from fishermen during other fishing opportunities. We were unable to obtain true quantitative samples because of the difficulty in estimating the volume of water filtered, the limited number of large jellyfish samples, and from bias by artificial selection by fishermen. However, we tried to cover all of the species collected during the fishing period to clarify the species composition of jellyfish in both commercially exploited and by those caught as by-catch. During collection, live animals were photographed onboard or underwater, and then a part of them was fixed with $5 \%$ formalin/seawater. In the laboratory, these animals were identified to species or genus level.

\section{Fishery statistics}

As per our request, two government-run companies, the Sea Product Processing Companies in Haiphong (Hai Phong) and Nam Dinh, kindly provided us with official data concerning the amount of jellyfish products exported by these companies.

\section{Results and Discussion}

\section{Catching jellies at sea}

The main fishing grounds of jellyfish are located approximately $4-5 \mathrm{~km}$ from the shore and $20-25 \mathrm{~km}$ along the sandy coast of the Quang Xuong District in Thanh Hoa, with a depth of $<20 \mathrm{~m}$ (Fig. 1). Fishing season begins from early April (the first week of the lunar month of March) and terminates at the end of May, corresponding to the appearance and disappearance of target jellyfish species. Fishermen say that the fishing period does not seem to change with year, at least since the early 1990's. The fishing season in Thanh Hoa is different to that reported from relatively close locations, i.e. Haiphong and Tongking Bay regions, where the season starts in July and ends in September (Omori \& Nakano 2001). The reason for the regular appearance of jellyfish in spring in Thanh Hoa remains unclear. However, the change in the direction of monsoon winds from northeast to east and southeast at this time of 
Table 1. The amount of export jellyfish at the Haiphong Sea Product Processing Company from 1995 to 2005 from various locations in Vietnam (see Fig. 1 for location).

\begin{tabular}{|c|c|c|c|c|c|c|c|}
\hline Year & $\begin{array}{l}\text { Total } \\
\text { (ton) }\end{array}$ & $\begin{array}{l}\text { Haiphong, } \\
\text { Quang Ninh } \\
\text { (ton) }\end{array}$ & $\begin{array}{l}\text { Thai Binh, } \\
\text { Nam Dinh } \\
\text { (ton) }\end{array}$ & $\begin{array}{c}\text { Thanh Hoa* } \\
\text { (ton) }\end{array}$ & $\begin{array}{l}\text { Nghe An, } \\
\text { Ha Tinh } \\
\text { (ton) }\end{array}$ & $\begin{array}{l}\text { Quang } \\
\text { Binh } \\
\text { (ton) }\end{array}$ & $\begin{array}{l}\text { Southern part } \\
\text { of Vietnam** } \\
\text { (ton) }\end{array}$ \\
\hline 1995 & 1500 & 100 & 100 & 500 & 500 & na & 300 \\
\hline 1996 & 2500 & 150 & 200 & 700 & 550 & 200 & 700 \\
\hline 1997 & 2600 & 400 & 200 & 800 & 600 & 200 & 400 \\
\hline 1998 & 2600 & 200 & 400 & 600 & 800 & 100 & 500 \\
\hline 1999 & 3600 & 300 & 500 & 700 & 700 & 200 & 1200 \\
\hline 2000 & 2900 & 400 & 600 & 900 & 500 & 200 & 300 \\
\hline 2001 & 4600 & 1700 & 400 & 800 & 800 & 400 & 500 \\
\hline 2002 & 2200 & 260 & 500 & 900 & 540 & na & na \\
\hline 2003 & 3500 & 300 & 450 & 900 & 800 & 100 & 950 \\
\hline 2004 & 4000 & 600 & 600 & 1000 & 700 & na & 1100 \\
\hline 2005 & 4600 & 800 & 1000 & 1600 & 800 & 100 & 300 \\
\hline Total & 34600 & 5210 & 4950 & 9400 & 7290 & 1500 & 6250 \\
\hline
\end{tabular}

na: not available

*Does not include the data from private companies (see Text).

**Exact location could not be confirmed.

the year may transfer surface-drifting animals from the north to south and from offshore to the coast (Wyrtki 1961). Also, the relatively high zooplankton abundance and biomass at the river mouths from Haiphong to Thanh Hoa may help sustain large jellyfish populations (Khoi \& Thom 1980, Khoi et al. 1995).

While the timing of their appearance does not show great inter-annual variability, the amount of the catch seems to vary largely by both day and year. According to Mr. Quang, the year 2006 was a poor year regarding the amount of jellyfish catch, while 2005 and 2007 were rich years. While there is no reliable data to demonstrate the variability in the amount of catch in the Thanh Hoa area, the official statistics on the amount of exported jellyfish products in Thanh Hoa recorded by the Haiphong Sea Product Processing Company shows a greater than three-fold difference in terms of metric tons during the 1995-2005 period (see Table 1), which would reflect the inter-annual variability in the amount of catch in this area.

Fishing is carried out only during the daytime. Fishermen usually use boats made of bamboo with a simple detachable motor (Fig. 2a). Styrofoam plates are also attached to increase buoyancy. The boats were not originally intended for collecting jellyfish, but are favored nevertheless because the boat has a short freeboard that is convenient to retrieve large heavy jellies from the water. The building cost of a boat is about $1-1.5$ million VND (=63-94 USD). Usually, 2 or 3 persons are onboard. Their main fishing gear is a drift floating gillnet that was originally developed for catching fishes (Fig. 2a and b). The most popular type of net is ca. $9-10 \mathrm{~m}$ in height and ca. $90-100 \mathrm{~m}$ in width with a mesh size of $10 \times 10 \mathrm{~cm}$. They also use hand-nets to collect surface jellies by hand.
Two target species were recognized and identified during our investigations: Rhopilema hispidum (Vanhöffen) (Fig. 2c) and Rhopilema esuculentum Kishinouye. Local fishermen call them "Sua Trang" which means "white jellyfish" and "Sua Do" which means "red jellyfish", respectively. These rhizostome species have already been reported as commercially exploited species in Southeast and East Asian waters (Omori 1981, Kingsford et al. 2000). In Thanh Hoa, $R$. hispidum can be caught much more abundantly than $R$. esuculentum (Fig. 2b). Fishermen say that usually only a single individual of Rhopilema esuculentum is found with a thousand individuals of $R$. hispidum in the net. The dominance of $R$. hispidum rather than $R$. esculentum is consistent with the previous reports on their geographical distribution. While $R$. hispidum occurs more in warmer waters in the Indo-west Pacific, from the southern part of Japan, south coasts of China to the Indian Ocean and Red Sea (Kramp 1961, Omori \& Nakano 2001), R. esculentum is distributed more to the north and in the Ariake Sea (Omori 1981), Po Hai, Yellow Sea and the East and South China Sea (Hon et al. 1978). Waters in northern Vietnam are within the main distributional range of $R$. hispidum, and $R$. esculentum occasionally occurs in Thanh Hoa, probably transported by the southward surface currents that prevail along the coasts of the South China Sea in March-May season (Wyrtki 1961).

According to the fishermen and Mr. Quang, since the start of the fishery in the early 1990's no other jellyfish species have ever been targeted in Thanh Hoa. During our investigation, Semaeostome scyphozoans, Cyanea sp., Chrysaora helvola Brandt, Sanderia sp. and the hydrozoan, Aequorea sp. were by-catch in the net, but they were not used for fishery products. Fishermen hate Cyanea sp. and 


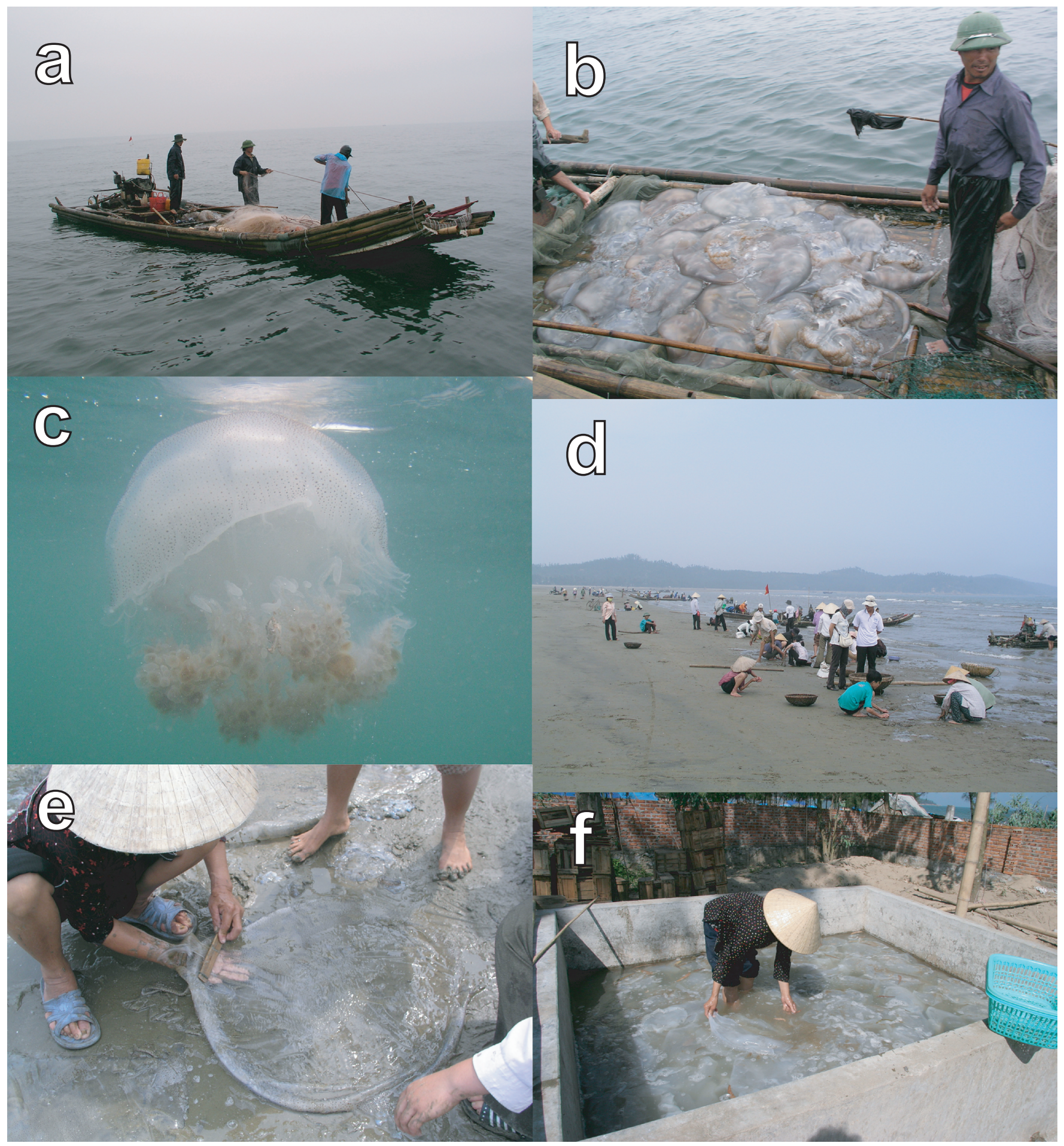

Fig. 2. Jellyfish fisheries and their processing in Thanh Hoa, Vietnam. (a) A fishing boat retrieving a net, (b) Deck of a fishing boat filled with jellyfish (Rhopilema hispidum), (c) Rhopilema hispidum, the most exploited species in Thanh Hoa, (d) On-beach processing of jellyfish, (e) Peeing off the surface skin of $R$. hispidum by a tool made of bamboo, (f) A processing pond for the bells at a jellyfish processing factory.

Chrysaora, called "Sua Ngua" which means itchy jellyfish, because they are harmful, relatively large, and believed not to be suitable for processing.

Fishermen do not always engage in jellyfish fisheries.
After jellyfish season finished in May, they shifted their target to mainly fishes using the same boat with the same nets, and the workers of the jellyfish processing factory (JPF) also changed their work to shrimp and fish processing. 


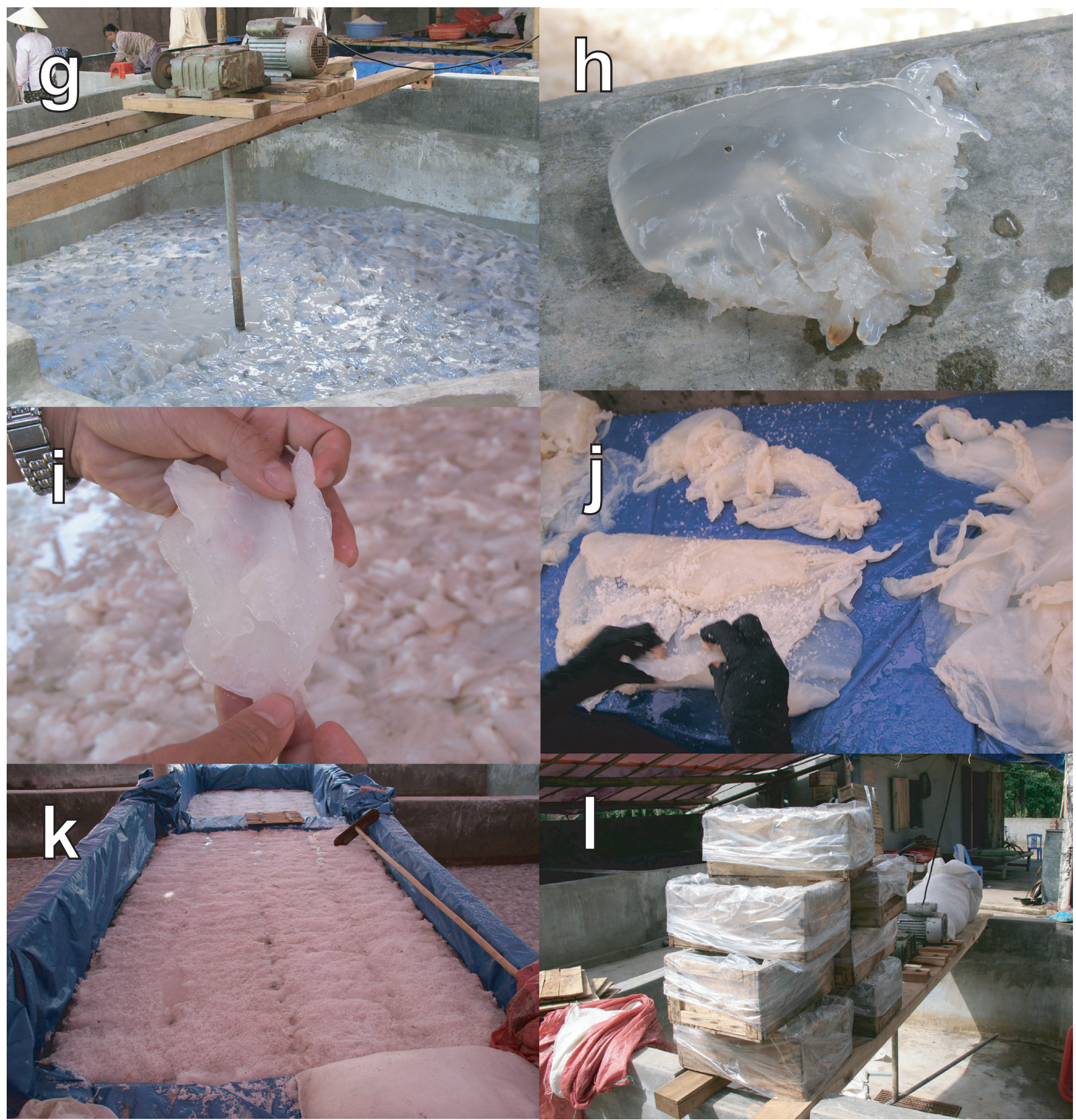

Fig. 2. (continue)

Jellyfish fisheries and their processing in Thanh Hoa, Vietnam. (g) A centrifuged pond for the oral-arms, (h) A oral-arm (semiprocessed), (i) A stem (semi-processed), (j) Piling bells, (k) A soaking pond for piled bells, (i) Wooden boxes for packing products. See text for more detailed explanations.

\section{Processing of jellies}

Jellyfish were first processed on the beach by laborers, mainly wives and children of the fishermen, waiting the return of the boats (Fig. 2d). The body of a jellyfish consists of a hemispherical umbrella (bell) and oral-arms that arise from the center part of the undersurface of the bell. Oralarms of rhizostome jellyfish are usually fused partly from the center of the undersurface of the bell. At first, the bell and oral-arms are separated. Because the bell of $R$. hispidum has numerous small surface denticulations, their bell surface is first peeled off using a tool made of bamboo 
(Fig. 2e). The subumbrellar epidermis and the contents of the gastrovascular cavity are also removed, and only the mesoglea is used. The oral-arms are separated into arms and the fused part of the oral-arms, called the 'stem' in this study, on the beach. These three parts, the bell, arms, and the stem, are processed independently with different procedures at the JPF.

The method of jellyfish processing at Mr. Quang's JPF was basically similar to that reported in previous literature using salt and alum $\left(\mathrm{AlK}\left[\mathrm{SO}_{4}\right]_{2} 12 \mathrm{H}_{2} \mathrm{O}\right)$ (Hon et al. 1978, Omori 1981, Hsieh et al. 2001). Salt reduces the water content of body tissues and keeps the products microbially stable (Hsieh et al. 2001), and alum aids in reducing $\mathrm{pH}$, and acts as a disinfectant and hardening agent, giving and maintaining a firm texture by precipitating protein (Huang 1988). Singulary use of salt or alum does not result in producing a product of satisfactory properties (Wootton et al. 1982).

\section{Bell processing}

After processing at the beach, the bells are transferred into an artificial pond at the JPF, which contains a solution of alum (5-10\% to the total weight of bell) and salt $(20-30 \%)$ (Fig. 2f). They are mixed around at 6-hour intervals until the next day. Bells in the ponds are then transferred into a workspace, in which the surface skins of the bells are visually inspected and the remaining epidermis are removed if found to be below acceptable quality. Bell margins are also cut off to remove marginal hard tissues. Bells are then piled, with salt inserted between bells (Fig. $2 \mathrm{j}$ ), and transferred into a pond containing alum and salt with the same concentrations as used in the first process. Salts are then added to increase salinity to the saturated level $(70 \%$ to the bell weight) and soaked for 1 week-1.5 months depending on the demand (Fig. 2k). Finally, the piled bells are removed from the pond and packed into wooden boxes with salt and are ready for shipment (Fig. 21).

\section{Oral-arm processing}

Oral-arms (without stems, Fig. 2h) are first transferred into a centrifuged pond containing fresh water (without chemicals or salt) in order to remove mucus and nematocysts; this is done for about 4 hours (Fig. 2g). The oralarms are then retrieved from the pond, rinsed with fresh water, and transferred into a pond containing alum (15\%) and salt (50\%) as is used for bell processing but at higher than initial concentrations. Salt and alum are then added every 5 hours until the concentrations become about 70 and $20 \%$ of the weight of the oral-arms, respectively. Oral-arms are then soaked in the same pond for 5 days. They are picked out of the pond, packed into wooden boxes with salt and are ready for shipment (Fig. 2. 1).

\section{Stem processing}

Stem processing is rather simple compared to that for the other parts of the jellyfishes (Fig. 2i). They are put into ponds containing alum (15\%) and salt $(50 \%)$ and soaked from 5 days to 1.5 months. No additional salt or alum is added during soaking. Stems are then stored with salt until being packed into wooden boxes with salt and becoming ready for shipment to market.

\section{Economical aspects of jellyfish fisheries and their possi- ble impacts on marine ecosystems}

Fishermen and Mr. Quang's JPF are financially independent; fishermen collect jellyfish and sell them to Mr. Quang. Wives of the fishermen usually engage in jellyfish processing on the beach and the JPF. In most cases, Mr. Quang pays cash to the fishermen on the beach after counting the number of the catch and evaluating the contents.

Rhopilema hispidum comprises a main source of income to the fishermen, although it is about 7-8 times cheaper than Rhopilema esuculentum for the price of a single animal. Mr. Quang says that the buying price of $R$. hispidum by the factory changes by year and location, roughly reflecting the market demands. In Thanh Hoa, it costs 7,000-8,000 VND animal ${ }^{-1}$ (=0.4-0.5 USD), and the price is more expensive than in Haiphong where 4,000-5,000 $\mathrm{VND}_{\text {animal }}^{-1}$ (=0.3 USD) is the average price. Rhopilema esuculentum can be sold at a much higher price of 50,000-60,000 VND animal ${ }^{-1}$ (=3.1-3.8 USD).

Catching large numbers of jellyfish provides great benefits to the fishermen. Each boat can earn 1.4-2.4 million VND day ${ }^{-1}$ (=87.5 USD), assuming that they can sell them at 7,000-8,000 VND animal $^{-1}$ i.e. the value for $R$. hispidum. Thus, the income of each fisherman would be $0.5-1.2$ million VND day $^{-1}$ (=29-75 USD) or 19-48 million VND during the season ( $=1,167-3,000$ USD), assuming that they work 40 days of the approximately 60 days of the fishery season. In addition, wives or children of fishermen work for the JPF to process jellyfish. According to Mr. Quang, they usually earn about 30,000-50,000 VND day ${ }^{-1}$ (=1.9-3.1 USD) depending on the amount of jellyfish they processed. These estimated values include many inaccuracies and assumptions, however we still believe that our estimation is not far from reality. During our interviews, we often heard from fishermen that only income from jellyfish could sustain them financially for the rest of the year.

On the other hand, the total income of the JPF was unknown. 5 JPFs (3 large and 2 small) exist in Thanh Hoa, and they were both technically and financially supported by Chinese or Koreans during the beginning stages of the fishery. After buying raw jellyfish at the beach, the private JPFs process and sell the jellyfish products to the brokers, mainly Chinese; the price of the products are kept secret. If the brokers stop buying the JPFs in Thanh Hoa will be unsustainable, primarily because the small private factories lack a 
trading route to export their product on their own.

According to Mr. Quang, the typical selling prices of the processed products of bells, oral-arms and stems of $R$. hispidum are 25,000, 21,500 and 12,000 $\mathrm{VND} \mathrm{kg}^{-1}$ (1.6, 1.3 and 0.8 USD), respectively. This indicates that the bell product can be sold at the most expensive prices compared to other parts, as suggested in Omori \& Nakano (2001). However, oral-arms require a much smaller amount of raw jellyfish than the bell to obtain the same yield of processed products, because raw bells exhibit a higher degree of shrinkage and more weight-loss than oral-arms during processing. Moreover, the processing of oral-arms is simpler and requires less labor than for bell processing. Mr. Quang stated that while Japanese brokers did not require oralarms, Chinese need them, and that has made oral-arms an important product in recent years.

Mr. Quang's factory employs ca. 40 workers during the jellyfish season. Once the jellyfish season has finished, he was able to earn enough money to build a new house, costing about 200 million VND (=12,500 USD, according to his comments). Up to now, jellyfish fisheries seem to provide a number of benefits to both a fishermen's family and the owner of a JPF, at least in Thanh Hoa. However, jellyfish fisheries also put them in a financially unstable condition, because they have to rely on both population dynamics of jellyfish, which show great inter-annual variability, and the market price set by the brokers who buy their product.

The total amount of catch during the jellyfish season at Thanh Hoa was roughly estimated. In Thanh Hoa, there were about a hundred boats going to the sea to catch jellyfish with 2-3 persons in each boat. A single boat can catch 200-300 jellyfish per day by means of going out to the sea and back to the shore, repeatedly. Based on this information provided by Mr. Quang and the fishermen, the number of Rhopilema jellyfish collected by fishermen in Thanh Hoa is estimated as $20,000-30,000$ indiv. day ${ }^{-1}$ or 800,000 $1,200,000$ indiv. per fishery period, assuming 40 days of fishing and a constant amount of catch. The removal of a million individuals of these large jellyfish within the period of two months in an area of about $125 \mathrm{~km}^{2}$ would be expected to have a considerable impact on the population dynamics of these animals, although we have no data to evaluate this point. Swarms of large gelatinous zooplankton can affect ecosystem structure through their predation on prey organisms (e.g. Mills 1995). While there is very limited knowledge on the feeding habits or feeding rates of these rhizostome species, they are considered to be plankton feeders using suctorial mouths, mainly feeding on microand meso-zooplankton such as bivalve and gastropod veligers, copepods and ciliates (Hon et al. 1978, Larson 1991). The effect of intensive exploitation of large edible jellyfish on the food-web structure of pelagic ecosystems should also be carefully evaluated.
Table 2. The amount of export jellyfish at the Thinh Long Sea Product Processing Company in Nam Dinh province from 2000 to 2005.

\begin{tabular}{lr}
\hline Year & Total (ton) \\
\hline 2000 & 1,827 \\
2001 & 1,290 \\
2002 & 850 \\
2003 & 2,224 \\
2004 & 1,895 \\
2005 & 6,948 \\
\hline Total & 15,034 \\
\hline
\end{tabular}

\section{Jellyfish fisheries statistics from northern Vietnam}

The amount of exploitation, processing and exporting jellyfish products in Vietnam, as a whole country, is still not evaluated in FAO statistics. However, the processing and exporting of jellyfish has been conducted by both governmental and private companies, and we successfully found statistical data that had been recorded by some governmentrun companies since 1995 (Tables 1 and 2).

According to the statistics provided by the Sea Product Processing Companies in Haiphong, one of the biggest governmental companies that export jellyfish products in Vietnam, the amount of jellyfish exported from various locations varied annually but tripled from 1,500 tones in 1995 to 4,600 tones in 2005 in total (Table 1). The other data source from the Sea Product Processing Companies in Nam Dinh indicated that the amount of jellyfish exported abroad also increased from 2000 to 2005, by four times (Table 2). These official data suggest a recent increase in the number of commercially harvested jellyfish in northern Vietnam, while exhibiting high inter-annual variation. However, the amount of jellyfish exported is likely higher than these official records, because there are private factories that have no records on their products.

According to records by the Tokyo Customs House, the amount of jellyfish imported to Japan from Vietnam between 1995-1999 ranged from 25.3 to 216.5 tons (Omori \& Nakano 2001). These values are an order of magnitude lower than the amounts recorded to be exported from northern Vietnam, suggesting that the main exporting country is not Japan.

\section{Conclusion-for achieving the better sustainability in fisheries}

Up to now, the jellyfish fishery in northern Vietnam seems to be successful. However, the fishery seems to be characterized by high variability in catch that is affected by both the biological characteristics of jellyfish and physical conditions. To achieve a more stable and sustainable condition in the jellyfish fishery, the accumulation of scientific knowledge on edible jellyfishes is required, as well as estab- 
lishing a monitoring system for physico-chemical oceanic conditions. To understand the factors controlling the stock size of jellyfish, studies on asexual reproduction, such as the strobilation ability in polyps in relation to environmental fluctuations, are essential. Lu et al. (1989) reported that strobilation of polyps and growth of ephyrae were greatest at salinities of 10-24 in Rhopilema esculentum. They concluded that marked decreases in the catch of this jellyfish occurred between 1973 and 1985, and that these were due to unusually high freshwater inputs into the estuaries in the former year that made the survival of planula and polyps less and depressed strobilation. This evidence suggests the importance of studying the biology of planula and polyps as well as monitoring the changes in salinity near the sea bottom to establish a better measure of predicting stability in jellyfish fisheries.

\section{Acknowledgements}

We are grateful to the reviewers for critical reading of the manuscript. We also thank the following people who helped in various capacities during this study: Dr. Shuhei Nishida and Mr. Chu Van Thuoc for their support in conducting this research; Mr. Vu Tien Quang kindly answered many questions repeatedly and permitted us to reveal his name in the paper; Local fishermen and workers at the JPF in Thanh Hoa provided valuable information on fisheries; Drs. Makoto Omori and Minoru Kitamura kindly provided old literature on the taxonomy and ecology of edible jellies; and Dr. Todd Miller for revisions on the manuscript. This study was supported by a grant from the Vietnamese Academy of Science and Technology to NTT, a grant from the Japanese Society for the Promotion of Science (JSPS) for the Multilateral Cooperative Research Program: Coastal Oceanography to JN and NTT, and a grant from JSPS Bilateral Joint Project 08038021-000001 to JN

\section{References}

Hon H-C, Chang S-M, Wang C-C (1978) Edible jellyfish. Science Publications, Beijing, 70 pp. (in Chinese)

Hsieh Y-HP, Leong F-M, Rudloe J (2001) Jellyfish as food. Hydrobiologia 451: 11-17.

Huang YW (1988) Cannonball jellyfish, Stomolophus meleagris as a food resource. J Food Sci 53: 341-343.
Kawahara M, Uye S, Ohtsu K, Iizumi H (2006) Unusual population explosion of the giant jellyfish Nemopilema nomurai (Scyphozoa: Rhizostomeae) in East Asian waters. Mar Ecol Prog Ser 307: 161-173.

Khoi NV, Cho N, Lam NN (1995) Review of studies on plankton in the sea waters of Vietnam during 70 years, 1924-1994. Coll mar res works VI: 81-90.

Khoi NV, Thom DT (1980) Zooplankton at the Nam Ha river mouth waters (in Vietnamese). Proc Mar stud 2: 111-132.

Kingsford MJ, Pitt KA, Gillanders BM (2000) Management of jellyfish fisheries, with special reference to the Order Rhizostomeae. Oceanogr Mar Biol 38: 85-156.

Kramp PL (1961) Synopsis of the medusae of the world. J Mar Biol Ass UK 40: 1-469.

Larson RJ (1991) Diet, prey selection and daily ration of Stomolophus meleagris, a filter-feeding scyphomedusa from the $\mathrm{NE}$ Gulf of Mexico. Est Coast Shelf Sci 32: 511-525.

Lu N, Liu C, Guo P (1989) Effect of salinity on larva of edible medusae (Rhopilema esculenta Kishinouye) at different development phases and a review on the cause of jellyfish resources falling greatly in Liaodong Bay. Act Ecol Sin 9: 304-309.

Matsueda N (1969) Presentation of Aurelia aurita at thermal power station. Bull Mar Biol Stn Asamushi 13: 187-191.

Mills CE (1995) Medusae, siphonophores, and ctenophores as planktivorous predatiors in changing global ecosystems. ICES J Mar Sci 52: 575-581.

Mills CE (2001) Jellyfish blooms: are populations increasing globally in response to changing ocean conditions? Hydrobiologia 451: 55-68.

Omori M (1978) Zooplankton fisheries of the world: a review. Mar Biol 48: 199-205.

Omori M (1981) Edible jellyfish (Scyphomedusae: Rhizostomeae) in the far east waters: a brief review of the biology and fishery (in Japanese with English abstract). Bull Plankton Soc Jpn 28: $1-11$.

Omori M, Nakano E (2001) Jellyfish fisheries in southeast Asia. Hydrobiologia 451: 19-26.

Purcell JE (2005) Climate effects on formation of jellyfish and ctenophore blooms: a review. J Mar Biol Ass UK 85: 461-476.

Purcell JE, Uye S, Lo WT (2007) Anthropogenic causes of jellyfish blooms and their direct consequences for humans: a review. Mar Ecol Prog Ser 350: 153-174.

Wootton M, Buckle KA, Martin D (1982) Studies on the preservation of Australian jellyfish (Catostylus spp.). Food Technol Aust 34: $398-400$.

Wyrtki K (1961) Physical oceanography of the Southeast Asian waters. Naga Rep 2: 1-195. 